\title{
CAN SIMPLE CONCUSSION OF THE BRAIN GIVE RISE TO OPTIC NEURITIS?
}

\author{
BY \\ L. B. Fleming, Captain R.A.M.C., \\ EYE SPECIALIST, BOMBAY BRIGADE.
}

ON January 2, 1919, E. J. was thrown from his horse whilst racing over hard ground, landed on the back of his head, and became unconscious; his memory for the following week was quite blank. On February 25, 1919, he began to have headaches, which gradually increased in severity, and at the end of March he was found to have optic neuritis. On April 1, 1919, a lumbar puncture was performed and 20 c.c. of cerebro-spinal fluid withdrawn; this relieved his headache.

On April 14, 1919, when I saw him, his condition was as follows: R. V., 6/12 and J. 6, with glasses $6 / 6$ and J. 1. L. V., 6/6 and J. 1, with glasses $6 / 6$ and J. 1 . R. E., margins of disc slightly blurred; swelling 1.5 D. Small amount of exudate round origin of vessels, and one haemorrhage on inferior nasal artery on disc. L. E., margins of disc slightly blurred; swelling of disc $0.75 \mathrm{D}$. One small haemorrhage immediately to temporal side of disc. Small inferior branch of superior temporal artery partly hidden by exudate. No other haemorrhage or exudate. B. E., veins full but not engorged; arteries on the small side. Apart from headaches there are no other symptoms.

As it appears that there is nothing beyond simple concussion to have produced the neuritis, it would be interesting to know if there are any other such cases on record.

\section{GUNSHOT INJURIES OF THE CORTICAL VISUAL AREAS}

\author{
BY \\ James Alexander Wilson, M.D.,
}

LATE RESIDENT SURGEON, THE LORD DERBY WAR HOSPITAL, WARRINGTON.

THE first of my cases is an example of temporary concussion amblyopia.

CASE 1.-Private S., while standing in a trench, was struck on the top of the head by a bullet. The missile produced a guttershaped scalp wound, about two inches long, just over the posterior part of the right parietal bone, but the bone itself was not fractured. Immediately "everything seemed black" to him, but he did not lose consciousness. Fifteen minutes later his vision began to 